\title{
Construction and Analysis of Plastic Extruder Machine for Polyethylene Plastic Waste
}

\author{
Muhammad Luthfi Sonjaya ${ }^{\mathrm{a}, *}$, Muh. Farid Hidayat ${ }^{\mathrm{a}, \mathrm{b}}$

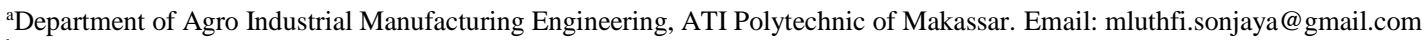 \\ b Department of Mechanical Engineering, Engineering Faculty, Hasanuddin University. Email: faridhidayat006@gmail.com
}

\begin{abstract}
Polyethylene plastic waste is such hazard object in the world, while the benefits of this plastic rubbish are prodigious. An extruder machine is one of the great ways to reduce huge amounts of plastic waste not only to the manufacturing companies which recycle the plastic waste but also to the small society. This extruder machine was created to overcome the problems faced by all countries about plastic waste in land or in ocean. The results of extruded plastic waste were solid filament that can be utilized for some valuable stuff made by plastic. From this study, experimental test was applied by heating the plastic waste with different temperatures of 150,160 , $170,180,190,200,210,220$, and $230^{\circ} \mathrm{C}$. As a result, the best temperature to heat the polyethylene plastic waste is $190^{\circ} \mathrm{C}$ according to surface roughness test and digital caliper measurement.
\end{abstract}

Keywords: Extruder machine; polyethylene plastic waste; surface roughness

\section{Introduction}

Plastic is material that has many functions in human's life. Firstly, most of our packaging for food uses plastic to cover the food. Many fast food restaurants, for instance, take advantage of using plastic in order to serve the meal. Secondly, household dishes are made by plastic because they are simple to utilize. Lastly, the furniture companies begin to produce family's needs in terms of chairs, desks, cupboards and others.

However, plastic becomes one of the environmental issues in the world because some people have not been able to use it wisely. [1] Still lots of plastic garbage lay strewn across the street in some parts of world. In addition, [2] plastic is also extremely dangerous for the ocean because plastic rubbish goes all the way to the sea for the last destination. The impact is a hazard to marine life. Million tons of plastic garbage are currently entering to the ocean every year from land through river mostly located in Asia [3]. On other impacts of plastic waste, it affects the condition on coral reefs which increase diseases that can threaten them [4].

Plastic extruder is a machine to recycle the plastic garbage to be something that is more valuable. The process of this machine is to extrude the plastic by heating process. The purpose of this machine is to reduce plastic garbage in the world and recycle plastic waste.

*Corresponding author. Tel.: +62-852-2446-0409

Jalan Sunu No. 220

Makassar, Indonesia, 90152

\section{Literature Review}

Plastic extruder mechanism consists of $5 \mathrm{~mm}$ threaded lead screw (worm screw). The plastic is fed from the hopper, letting it fall on the thread. As indicated by the direction, the plastic is going forward. With the help of the heater pad, it melts as it moves forward. The heater pad is heated to $350{ }^{\circ} \mathrm{C}$. The molten plastic is moved forward and from the nozzle it is collected [5], [6].

There are plenty of things that extruder machine can create from plastic waste. Brick is one example of utilizing plastic garbage. [7], [8] By using different kinds of plastic with various combinations to create different kinds of bricks, researchers believe the different properties of bricks through conducting different tests on them. The most popular test performed on bricks involves compression and water absorption testing.

In addition, Due to the extreme quick emergence of this innovation, leaps have been created towards enhancing manufacturing. Ideally, the invention of screw extrusion would open doors to new $3 \mathrm{~d}$ printing concepts. Screw extrusion would allow people to access a larger range of high-resolution products for their 3D printed parts [9].

In the field including researchers, manufacturers, designers, engineers and scientists, 3D printing technology is becoming famous each day, and FDM is the most commonly utilized 3D printing technology. The purpose of the project was to design and develop a Bowden Extruder based on FDM. Researchers built a Bowden extruder that was simple and user-friendly. 
Researchers found that the prints are almost consistent with the extruder [10].

In the research, [11] a model feedback control system has been developed and experimentally tested to regulate the temperature and pressure of the component in a single screw extruder. Through a simple yet effective control architecture focused on two separate external SISO loops and seven identical internal SISO loops for local temperature control, actual-time temperature and pressure regulation was effectively accomplished.

Based on Labview and Matlab/ Simulink, the plastic extruder's constructed semi-physical actual-time simulation system for temperature control was implemented. The study proved that even in the plastic extruder production line, the HIL simulation technique and our designed temperature control computer program had an amazing effect [12]. The discover through simulation also expressed the potential to complement many other determinations by means of extended analytics; affective synchronization and in-situ identification such as injection fill time; packing injection ramp speed, operating temperatures, reliability, etc. [13]. The simulation method can be commonly used in the design of the process control system, it can not only shorten the development cycle and cost, increase the design quality of the control system, but also provide a solution for the real-time display of the controller [12].

Indicators of extruded plastic waste have been studied. Mechanical and chemical parameters of recycling solid plastic waste have been researched [14], [15], [16]. The laminates of textile cotton waste plastic were researched in order to understand characterization of tensile and fatigue [17], [18]. The properties of lowisotacticity polypropylene elastomeric fibers with purpose of spinning were inscribed [19], also plastic bag waste to use ecofriendly polyethylene fiber was studied [20].

The result of plastic extruder machine should be analyzed by the measurement of surface roughness. This aims to determine best results of the machine according to the temperature tested. Surface roughness test for plastic composites by applying an optical method was measured [21]. Furthermore, plastic pipes that were used for irrigation were calculated experimentally using internal surface roughness test [22].

\section{Design and Procedure of Machine}

The tools used in this research as shown in Fig. 1 are: electrical welding machine, safety goggles, welding gloves, heat resistant gloves, mechanical tools (wrench, pliers, and hammer), measuring tools (ruler, varnier caliper, micrometer, surface roughness test and dial indicator), conventional machines (turning, milling, grinding, drilling, and shaping), computer set, power supply, and CNC milling machine.

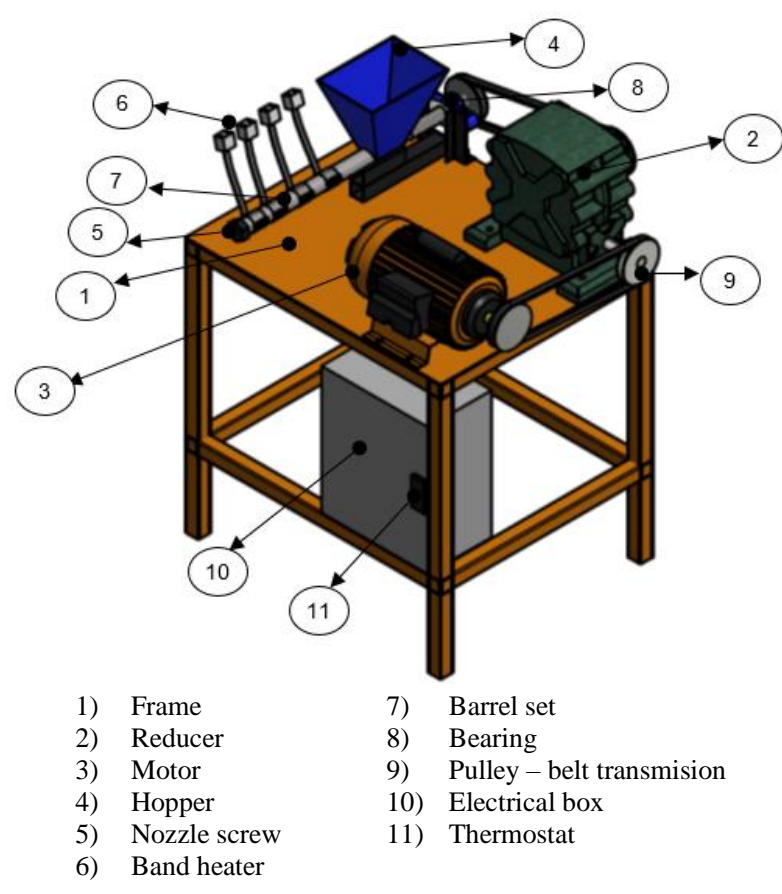

Figure 1. Design of Plastic Extruder Machine

The main function of this machine is to heat the plastic to become filament extruded. A part to heat the plastic is barrel that is connected with hopper. The material that is used for barrel is steel. In order to drive the plastic out, screw is paired up inside barrel. In Fig. 2 (c), nozzle is a part to mold the extruded plastic after heating the plastic. The size of nozzle circle is $\varnothing 4 \mathrm{~mm}$. it means the size result of solid filament should be around 4 $\mathrm{mm}$ in diameter.

In this study, the average of motor rotation is 30 RPM. This is from AC motor with $1 / 4 \mathrm{HP}$. Before motor connected to screw driver, there is reducer $1: 20$ to decrease the rotation from AC motor. Pulley -belt transmission is applied in this machine. The heat source of barrel is band heater. There are 3 band heaters used with the distance among band heaters $32 \mathrm{~mm}$. To control the temperature, thermocouple and thermostat are attached. The function of thermocouple is to measure the temperature of barrel while thermostat is to set the temperature.

The steps in order to operate this extruder machine is (1) Connect electrical box to power supply, (2) switch MCB on from electrical box, (3) set temperature by using thermostat, (4) wait until the temperature reaches the maximum set, (5) after reaching the temperature, turn on motor to rotate barrel screw, (6) enter plastic shredded from shredder machine into the hopper, (7) prepare a container to place the result of extruding. 


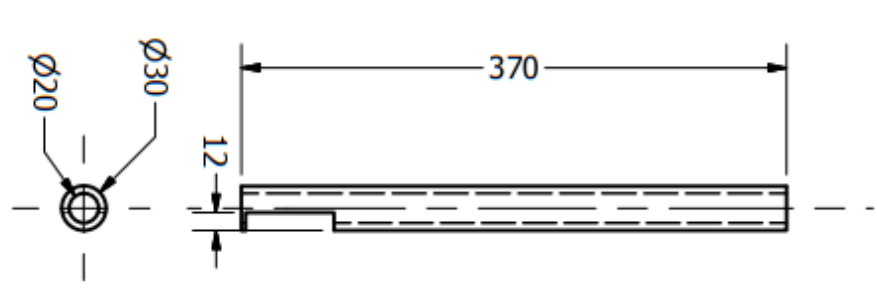

(a)

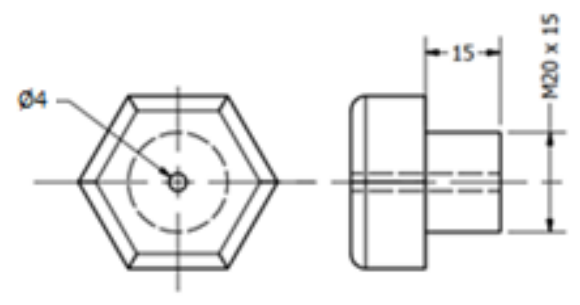

(b)

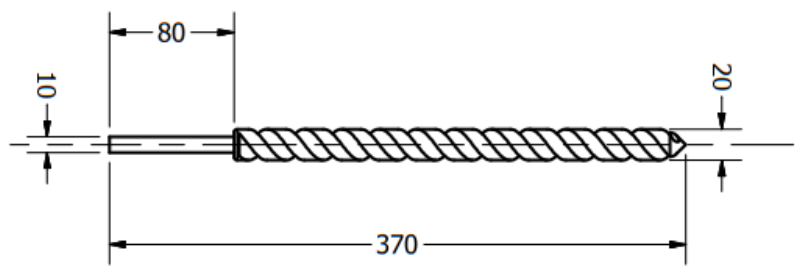

(c)

Figure 2. Design of (a) barrel (b) screw (c) nozzle

\section{Result and Discussion}

\subsection{Construction and operation result of plastic extruder machine}

The frame of plastic extruder machine in Fig. 3 is assembled by electrical welding machine. The position of main tools of this machine is on the frame while the electrical box is on one side of the frame. Miniature circuit breaker is inside the electrical box. It has function to run the machine with red lamp as a sign.

There were two buttons on the electrical box in its front door. A left button is for running AC motor and a right button for turning off $\mathrm{AC}$ motor. On front door of electrical box, thermostat was available in order to show the temperature of barrel.

In the experimental test, polyethylene plastic waste was tested. Each experiment contained 30 gram plastic waste of polyethylene. The variation of this research was from temperature 150, 160, 170, 180, 190, 200, 210, 220, and $230^{\circ} \mathrm{C}$. In order to get the time to melt plastic, estimated time was counted by using stopwatch. It started from pouring plastic waste to melting the plastic out from the nozzle. It was noted that while pouring waste plastic into the hopper, motor was on to rotate screw driver. In order to describe the result of filament, molten results were taken into two categories. One category is solid which means if the samples are extruded well or no, and another is continue which means whether the samples are consistent or inconsistent.
Table 1 shows the data of extruding plastic waste with various hot temperatures. According to the experimental test, the filament with temperatures of degree 150 and 160 was not melted at all due to low heat from the barrel as heater of plastic waste. While the filament samples with higher temperature $(170,180,190$, $200,210,220$ and $230^{\circ} \mathrm{C}$ ) were melted. However, some samples of filament such as the temperature of 210, 220 and $230^{\circ} \mathrm{C}$ were inconsistent in extruding process. The high temperatures also produced darker filament results of extruding process (see Fig. 4). It occurred because heat of the barrel was too high. Furthermore, a sample of $230^{\circ} \mathrm{C}$ produced not only unstable extruded plastic but also liquid plastic that are different with other samples.

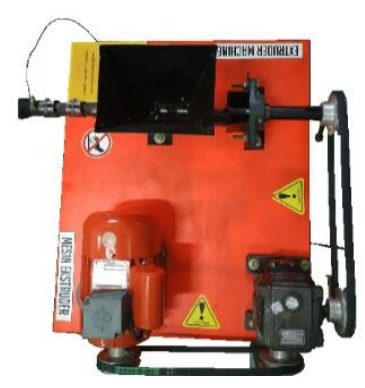

(a)

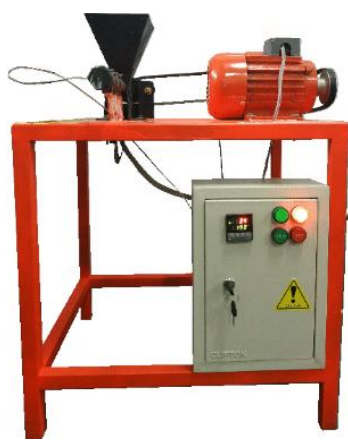

(b)
Figure 3. Construction of plastic extruder machine (a) top view (b) front view

Table 1. Data of extruding process on plastic waste

\begin{tabular}{|c|c|c|c|c|c|c|}
\hline \multirow[b]{2}{*}{ No. } & \multirow{2}{*}{$\begin{array}{c}\text { Temperature } \\
\left({ }^{\circ} \mathrm{C}\right)\end{array}$} & \multirow{2}{*}{$\begin{array}{c}\text { Time from } \\
\text { Pouring Plastic to } \\
\text { Melting Plastic } \\
\text { (Minute) }\end{array}$} & \multicolumn{2}{|c|}{ Molten Result } & \multirow{2}{*}{$\begin{array}{l}\text { Total Time } \\
\text { (Minute) }\end{array}$} & \multirow[b]{2}{*}{ Annotation } \\
\hline & & & Solid & Continue & & \\
\hline 1. & 150 & - & & & 600 & No Molten Plastic \\
\hline 2. & 160 & - & & & 600 & No Molten Plastic \\
\hline 3. & 170 & 204 & Yes & Yes & 1616 & \\
\hline 4. & 180 & 150 & Yes & Yes & 1048 & \\
\hline 5. & 190 & 125 & Yes & Yes & 896 & \\
\hline 6. & 200 & 70 & Yes & Yes & 558 & \\
\hline 7. & 210 & 88 & Yes & No & 473 & \\
\hline 8. & 220 & 55 & Yes & No & 363 & \\
\hline 9. & 230 & 41 & No & No & 297 & \\
\hline
\end{tabular}


Table 1 shows the data of extruding plastic waste with various hot temperatures. According to the experimental test, the filament with temperatures of degree 150 and 160 was not melted at all due to low heat from the barrel as heater of plastic waste. While the filament samples with higher temperature (170, 180, 190, 200, 210, 220 and $230^{\circ} \mathrm{C}$ ) were melted. However, some samples of filament such as the temperature of 210, 220 and $230^{\circ} \mathrm{C}$ were inconsistent in extruding process. The high temperatures also produced darker filament results of extruding process (see Fig. 4). It occurred because heat of the barrel was too high. Furthermore, a sample of $230^{\circ} \mathrm{C}$ produced not only unstable extruded plastic but also liquid plastic that are different with other samples.

Duration of the time from pouring the plastic waste into the hopper to melting plastic waste was measured. This aims to know plastic which melts slower and faster by different heating temperature with similar weight of plastic (30 gr). It can be shown from Table 1 that a temperature of $170^{\circ} \mathrm{C}$ was slower than other temperature. On the other hand, a temperature of $230^{\circ} \mathrm{C}$ was the most rapid to heat the plastic. It means that the hotter barrel is, the faster melting time is. Total time needed in melting plastic was also measured. From the study, experiments with temperatures of 170,180 , and $190^{\circ} \mathrm{C}$ needed longer time to finish $30 \mathrm{gr}$-plastic waste. While samples heated on temperatures of $200,210,220$ and $230^{\circ} \mathrm{C}$ only needed no more than 600 minutes.

\subsection{Analysis of filament size}

Various heating temperature causes the size change of filaments. In this research, Digital caliper Mitutoyo CD6" ASX with serial number of B17012083 was used to get real inspection in measuring. The caliper measuring range is up to $150 \mathrm{~mm}$ with minimum indication of $0.01 \mathrm{~mm}$. As explanation above, the size of each sample should be around $4 \mathrm{~mm}$ in diameter because of nozzle circle size $4 \mathrm{~mm}$. From Table 2, samples which have suitable size with nozzle pit are 180,190 and $200^{\circ} \mathrm{C}$. The average size value of the samples is more than $4 \mathrm{~mm}$ which means that plastic waste extruded fully, while samples with temperature of 170,210 and $220^{\circ} \mathrm{C}$ were partially melted due to less size of $4 \mathrm{~mm}$ in average.

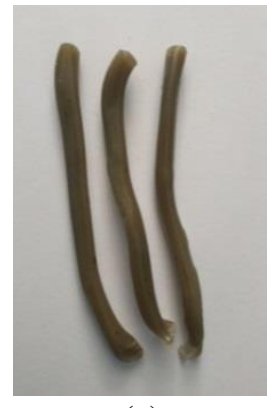

(a)

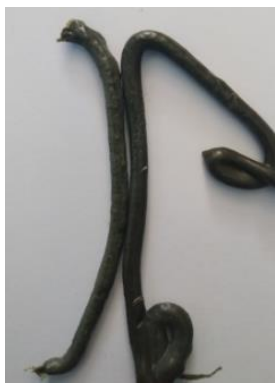

(e)

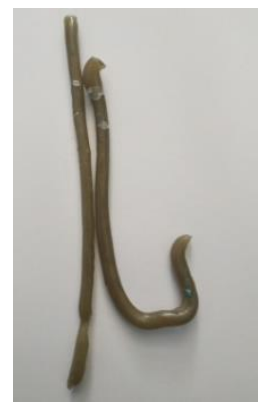

(b)

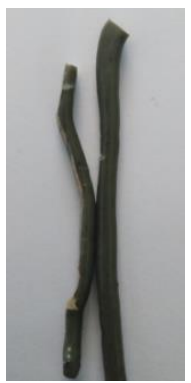

(f)

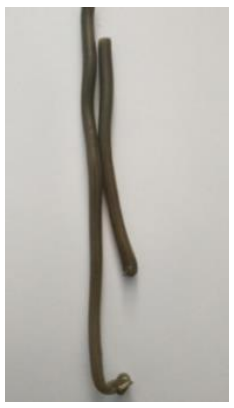

(c)

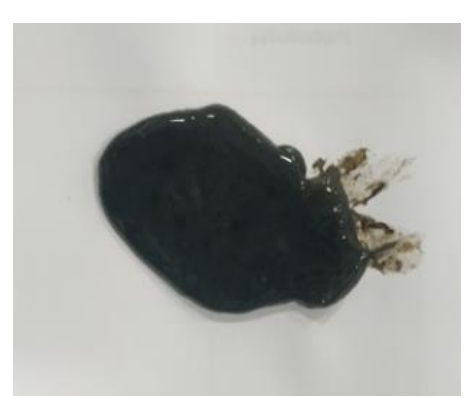

(g)

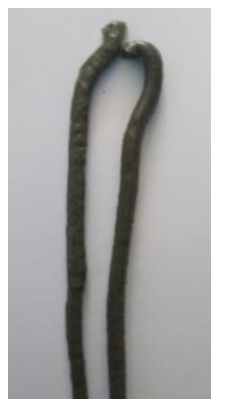

(d)

Figure 4. Result of melting by different temperature

(a) $170^{\circ} \mathrm{C}$ (b) $180^{\circ} \mathrm{C} \mathrm{(c)} 190^{\circ} \mathrm{C}$ (d) $200^{\circ} \mathrm{C}$ (e) $210^{\circ} \mathrm{C}$ (f) $220^{\circ} \mathrm{C}$ (g) $230^{\circ} \mathrm{C}$

Table 2. Data of filament size

\begin{tabular}{|c|c|c|c|c|c|c|c|}
\hline \multirow{2}{*}{$\begin{array}{c}\text { Temperature } \\
\left({ }^{\circ}\right)\end{array}$} & \multirow{2}{*}{$\begin{array}{l}\text { Measuring } \\
\text { (Times) }\end{array}$} & \multicolumn{2}{|c|}{$\begin{array}{c}\text { Diameter of Solid Filament } \\
(\mathbf{m m})\end{array}$} & \multirow{2}{*}{$\begin{array}{c}\text { Temperature } \\
\left({ }^{\circ}\right)\end{array}$} & \multirow{2}{*}{$\begin{array}{l}\text { Measuring } \\
\text { (Times) }\end{array}$} & \multicolumn{2}{|c|}{$\begin{array}{c}\text { Diameter of Solid Filamen } \\
(\mathbf{m m})\end{array}$} \\
\hline & & Value & Mean & & & Value & Mean \\
\hline \multirow{3}{*}{170} & 1 & 3.15 & \multirow{3}{*}{3.29} & \multirow{3}{*}{200} & 1 & 4.67 & \multirow{3}{*}{4.34} \\
\hline & 2 & 3.58 & & & 2 & 4.15 & \\
\hline & 3 & 3.13 & & & 3 & 4.19 & \\
\hline \multirow{3}{*}{180} & 1 & 4.19 & \multirow{3}{*}{4.36} & \multirow{3}{*}{210} & 1 & 4.18 & \multirow{3}{*}{3.79} \\
\hline & 2 & 4.76 & & & 2 & 3.89 & \\
\hline & 3 & 4.14 & & & 3 & 3.30 & \\
\hline \multirow{3}{*}{190} & 1 & 4.98 & \multirow{3}{*}{4.88} & \multirow{3}{*}{220} & 1 & 4.93 & \multirow{3}{*}{3.60} \\
\hline & 2 & 4.85 & & & 2 & 2.95 & \\
\hline & 3 & 4.81 & & & 3 & 2.93 & \\
\hline
\end{tabular}




\subsection{Analysis of surface roughness test}

In order to survey the result of melted plastic waste, analysis of roughness surface from filament is important to measure. Portable surface test machine SJ-310 Mitutoyo (Fig. 5) was operated in this study. The surface roughness was used after the filament has been got from the extruder machine. Roughness measurements were repeated into three times with different surface of each sample to rise up the reliability. Values of surface roughness measurements were recorded by $\mathrm{Ra}$ and $\mathrm{Rq}$ where; $\mathrm{Ra}$ is the deviation of arithmetic average from the samples analyzed in $\mu \mathrm{m}$, and $\mathrm{Rq}$ is the root mean square average of the profile heights over the evaluation length in $\mu \mathrm{m}$. The standard of measurement used in the surface roughness test was ISO1997. The speed of detector to take the data was $0.5 \mathrm{~mm} / \mathrm{second}$. Sampling length of the test was $0.8 \mathrm{~mm}$.
Table 3 shows parameters of surface roughness test on all samples with various temperatures. Data taken from this study were mean roughness value (Ra) and root mean square average (rq). In this experimental test, three times tests were required in different surfaces to get the reliability. From test 1 to test 3 for all the samples, Ra and $\mathrm{Rq}$ value were not overly far. This means that the surfaces on all samples were almost similar.

Figure 6 presents comparison of Ra data from surface roughness test. It can be seen that the average better value of $R a$ surface roughness from all the samples was the sample with temperature of $190^{\circ} \mathrm{C}$, followed by samples of 180 and $170^{\circ} \mathrm{C}$, while samples of 200 and $210^{\circ} \mathrm{C}$ got higher arithmetic deviation in average. However, the sample of $220^{\circ} \mathrm{C}$ had average low $R a$. This was because the extruding process was inconsistent.

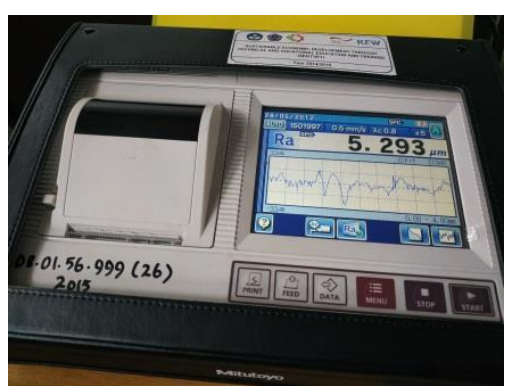

(a)

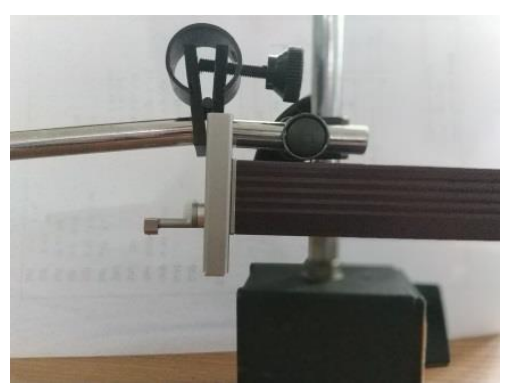

(b)

Figure 5. (a) Portable surface roughness testing machine SJ-310 Mitutoyo

(b) detector of surface roughness attached by dial indicator base

Table 3. Data of surface roughness test

\begin{tabular}{|c|c|c|c|c|c|}
\hline \multirow{2}{*}{$\begin{array}{c}\text { Temperature } \\
\left({ }^{\circ} \mathbf{C}\right)\end{array}$} & \multirow{2}{*}{$\begin{array}{l}\text { Testing } \\
\text { (times) }\end{array}$} & \multicolumn{2}{|c|}{$\operatorname{Ra}(\mu \mathbf{m})$} & \multicolumn{2}{|c|}{$\mathbf{R q}(\mu \mathbf{m})$} \\
\hline & & Value & Mean & Value & Mean \\
\hline \multicolumn{6}{|l|}{150} \\
\hline \multicolumn{6}{|l|}{160} \\
\hline \multirow{4}{*}{170} & 1 & 0.914 & & 1.253 & \\
\hline & 2 & 1.007 & 0.999 & 1.463 & 1.383 \\
\hline & 3 & 1.077 & & 1.433 & \\
\hline & 1 & 1.028 & & 1.233 & \\
\hline \multirow[t]{3}{*}{180} & 2 & 0.898 & 0.940 & 1.187 & 1.173 \\
\hline & 3 & 0.895 & & 1.101 & \\
\hline & 1 & 0.545 & & 0.698 & \\
\hline \multirow[t]{3}{*}{190} & 2 & 0.565 & 0.586 & 0.707 & 0.731 \\
\hline & 3 & 0.648 & & 0.788 & \\
\hline & 1 & 3.674 & & 5.170 & \\
\hline \multirow[t]{3}{*}{200} & 2 & 3.638 & 3.317 & 5.139 & 4.498 \\
\hline & 3 & 2.640 & & 3.185 & \\
\hline & 1 & 3.890 & & 4.818 & \\
\hline \multirow[t]{3}{*}{210} & 2 & 3.285 & 3.895 & 4.140 & 4.870 \\
\hline & 3 & 4.510 & & 5.654 & \\
\hline & 1 & 0.845 & & 1.124 & \\
\hline \multirow[t]{2}{*}{220} & 2 & 0.912 & 0.828 & 1.179 & 1.083 \\
\hline & 3 & 0.728 & & 0.947 & \\
\hline
\end{tabular}




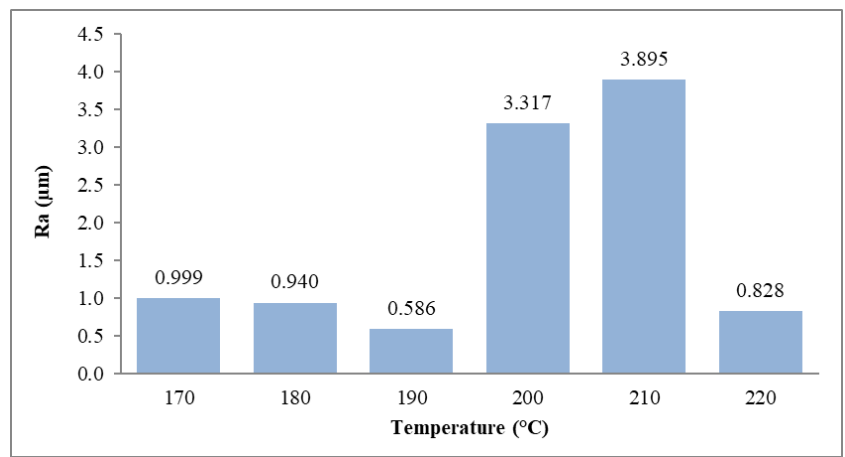

Figure 6. Comparison of arithmetic average deviation ( $\mathrm{Ra}$ ) among the temperatures of $170,180,190,200,210$ and $220^{\circ} \mathrm{C}$

\section{Conclusion}

In this research, the mechanical design and the construction of an extruder machine were built to reduce polyethylene plastic waste. The result of this machine was solid filament from polyethylene plastic waste that can be used for some valuable stuff such as furniture, household appliances or other things made from plastic. In order to get better solid filament, digital caliper measurement and surface roughness test were applied with different samples from various temperatures of barrel as heater of plastic waste. According to the research, a sample with temperature of $190^{\circ} \mathrm{C}$ had the greatest value of surface roughness test and showed solid size with constant diameter.

\section{Acknowledgements}

The authors would like to thank to the Edinburgh University for the grant of the research under Global Challenges Research Fund Project.

\section{References}

[1] R. C. Thompson, S. H. Swan, C. J. Moore, and F. S. Vom Saal, "Our plastic age," Philos. Trans. R. Soc. B Biol. Sci., vol. 364, no. 1526, pp. 1973-1976, 2009.

[2] J. R. Jambeck, Q. Ji, Y.-G. Zhang, D. Liu, D. M. Grossnickle, and Z.-X. Luo, "Plastic waste inputs from land into the ocean," Science (80-. )., vol. 347, no. 6223, pp. 764-768, 2015.

[3] L. C. M. Lebreton, J. Van Der Zwet, J. W. Damsteeg, B. Slat, A Andrady, and J. Reisser, "River plastic emissions to the world's oceans," Nat. Commun., vol. 8, pp. 1-10, 2017.

[4] G. Bidegain and I. Paul-Pont, "Commentary: Plastic waste associated with disease on coral reefs," Front. Mar. Sci., vol. 5, no. JUL, pp. 26-29, 2018.

[5] L. B. Variya, M. Bhavik, P. Harshil, P. Jenish, and G. Hardik, "Plastic Extruder Machine," vol. V, no. 02, pp. 53-54, 2018.
[6] H. Janeschitz-Kriegl, J. Schijf, and J. A. M. Telgenkamp, "A temperature probe for flowing polymer melts," J. Sci. Instrum., vol. 40, no. 8, pp. 415-419, 1963.

[7] R. S. Kognole, K. Shipkule, and K. S. | M. P. | L. P. | U. Survase, "Utilization of Plastic waste for Making Plastic Bricks," Int. J. Trend Sci. Res. Dev., vol. Volume-3, no. Issue-4, pp. 878-880, 2019.

[8] J. P. Modak, V. V. Sohoni, and H. V. Aware, "Manually powered manufacture of keyed bricks," Build. Res. Inf., vol. 25, no. 6, pp. 354-364, 1997.

[9] M. H. Wankhade and S. G. Bahaley, "Design and Development of Plastic Filament Extruder for 3D Printing," IRA-International $J$. Technol. Eng. (ISSN 2455-4480), 2018.

[10] M. Hoque, H. Kabir, and M. H. Jony, "Design and Construction of a Bowden Extruder for a Fdm 3D Printer Uses 1.75Mm Filament," Int. J. Tech. Res. Sci., vol. 3, no. VIII, 2018.

[11]F. Previdi, S. Savaresi, and A. Panarotto, "Design of a feedback control system for real-time control of flow in a single-screw extruder," IFAC Proc. Vol., vol. 16, pp. 454-459, 2005.

[12] J. Xu, G. Zuo, J. Chen, and M. Wan, "A rapid control prototyping system design for temperature control of plastic extruder based on labview," in 2011 International Conference on Electronics, Communications and Control, ICECC 2011 - Proceedings, 2011.

[13] M. Lakkanna, G. C. Mohan Kumar, and R. Kadoli, "Computational design of mould sprue for injection moulding thermoplastics," $J$. Comput. Des. Eng., vol. 3, no. 1, pp. 37-52, 2016.

[14]K. Ragaert, L. Delva, and K. Van Geem, "Mechanical and chemical recycling of solid plastic waste," Waste Manag., vol. 69, pp. 24-58, 2017.

[15]C. L. Wu, M. Q. Zhang, M. Z. Rong, and K. Friedrich, "Tensile performance improvement of low nanoparticles filledpolypropylene composites," Compos. Sci. Technol., vol. 62, no. 10-11, pp. 1327-1340, 2002.

[16]J. Z. Liang and Q. Q. Yang, "Mechanical properties of carbon black-filled high-density polyethylene antistatic composites," $J$. Reinf. Plast. Compos., vol. 28, no. 3, pp. 295-304, 2009.

[17]R. Petrucci et al., "Tensile and fatigue characterisation of textile cotton waste/polypropylene laminates," Compos. Part B Eng., vol. 81, pp. 84-90, 2015.

[18] J. J. Hwang, T. Adachi, T. Kuwabara, and W. Araki, "Laminate model expressing mechanical properties of polypropylene foams having non-uniform cell-shape distributions," Mater. Sci. Eng. A vol. 487, no. 1-2, pp. 369-376, 2008

[19] Y. Kohri, T. Takebe, Y. Minami, T. Kanai, W. Takarada, and T. Kikutani, "Structure and properties of low-isotacticity polypropylene elastomeric fibers prepared by sheath-core bicomponent spinning: Effect of localization of high-isotacticity component near the fiber surface," J. Polym. Eng., vol. 35, no. 3, pp. 277-285, 2015.

[20]A. S. Soekoco, Noerati, M. Komalasari, Kurniawan, and A. Hananto, "Characterization of ecofriendly polyethylene fiber from plastic bag waste," AIP Conf. Proc., vol. 1868, 2017.

[21]N. Duboust et al., "An optical method for measuring surface roughness of machined carbon fibre-reinforced plastic composites,' J. Compos. Mater., vol. 51, no. 3, pp. 289-302, 2017.

[22]H. S. Da Rocha, P. A. A. Marques, A. P. De Camargo, J. A. Frizzone, and E. Saretta, "Internal surface roughness of plastic pipes for irrigation," Rev. Bras. Eng. Agric. e Ambient., vol. 21, no. 3, pp. 143-149, 2017. 